\title{
Applied conversation analysis for counselling and psychotherapy researchers \\ Perspectives article
}

Over several years, we have been undertaking collaborative research projects using language-based approaches to address research problems in mental health, with much of this work drawing upon Conversation Analysis (henceforth CA). Through our partnerships with a broad range of practicing professionals in psychiatry, psychology, counselling, and Allied Health, we have worked to demonstrate the value of closely studying language as a means of: 1) better understanding social interactions that take place in clinical settings, 2) improving practice, and 3) utilising best practices to inform care. CA provides empirical evidence that demonstrates the process of therapeutic change (Strong et al., 2008), as it allows researchers to closely attend to communication that impacts therapeutic practices and thereby patient outcomes (Priebe \& McCabe, 2008).

In this article, therefore, we argue for the value of using CA, specifically Applied $\mathrm{CA}$, for the close study of therapy and counselling. The reason for this, is that from our perspective, methodological approaches that focus on the close study of language make 'intuitive sense' as therapy is fundamentally a form of conversation (McLeod, 2001, p.91). Furthermore, it is well-accepted that clinicians need competencies in the art of good communication to facilitate positive therapeutic relationships (Priebe \& McCabe, 2008). In therapeutic settings, the language used can become the focus for transforming everyday descriptions and re-contextualising them into therapeutically relevant understandings (Roy-Chowdhury, 2006). And, importantly, as Strong et al. (2008) noted: "conversation is usually seen as part of the therapeutic process and evidence is viewed as outcome. Process (conversation) affects outcome (evidence); both are intertwined and inseparable" (p. 388).

\section{What is CA?}


In this article, we focus on the utility of 'Applied CA', as an 'applied' application is arguably more relevant for practitioners due to its emphasis on providing evidence to impact practice (Lester \& O'Reilly, 2019). For clarity, there are two broad types of CA: 1) traditional (or 'pure'), which studies mundane/ordinary conversations (e.g., conversations taking place over dinner); and 2) applied, which focuses predominantly (albeit not exclusively) on conversations that occur in institutional settings (e.g., therapy conversations). While there are different approaches to Applied CA (Antaki, 2011), here we attend specifically to a version of Applied CA that can directly inform clinical practice.

Broadly, CA is a qualitative methodology, rooted in the hermeneutic tradition, closely associated with the discursive turn (Tseliou, 2013); that is, the synthesis of approaches that focus on language and discourse, and one that critically assessed what was a dominant positioning of the individual, cognition and methods of experimentation (Bozatzis and Dragonas, 2011). In other words, the discursive turn reflected a shift in thinking, and proposed all human encounters are meaningful, bound by social interaction norms, and a focus on discourse straddles the boundaries between "social orders and their cultural realizations" (Harrè, 2003, p.695). This reflected a new paradigm in the social sciences, as analysts began to move away from focusing on individuals and their cognitive/mental states, to exploring social structures and conversational meanings that were constructed between interlocutors. $\mathrm{CA}$, became one of the methodological approaches that embraced this position, and focused its attention on social interaction, language and meaning, through its social constructionist epistemology.

This had useful implications for therapy and counselling, and for research in this field, as CA provides a flexible way to facilitate an understanding of how therapists and clients make sense of the therapeutic process, by showing how the therapeutic interaction unfolds within the conversational turns (Kiyimba \& O'Reilly, 2016). In other words, CA researchers attend closely to the language 
used in therapy, examining the conversational turns of both the clinician and the client to explore the sequential nature of therapeutic conversations. This is facilitated by the value that analysts place on collecting naturally-occurring data. Put simply, naturally-occurring data are recordings of activities or text-based documents generated naturally in society (Kiyimba et al., in press), and as such would still occur without the influence of the researcher (Potter, 2002). This is different from researcher-generated data, which only exists because of the researcher, such as interviews or surveys.

Through collecting data of this kind, analysts can pay attention to what is actually going on in the talk; that is the social actions being performed (e.g., excusing, blaming, defending, and so on) to see how therapy unfolds. In other words, analysts collect real-world data, real instances of therapy, as this practice-based evidence allows a reflection on how things are done within this institutional environment, so that best practices can be observed, and recommendations made. A frequently cited good example is the work of Heritage and Robinson, (2011), who examined primary care interactions, and showed that one simple word could impact on whether patients presented additional concerns; that is, asking if there was anything else was negatively slanted and would generally not elicit further talk, but asking if there was something else could. In our own work on mental health practice, we have shown that using the discursive device 'you said' before asking a question worked well to encourage children and young people to elaborate on sensitive topics (Kiyimba \&O'Reilly, in press).

\section{Why is CA Valuable for Practice?}

Making recommendations and analytic claims that inform practice are only possible because CA is based directly on the observable properties of conversational data (Drew et al., 2001), with evidence for therapists and counsellors being grounded in their real-world practices. In our view, this is especially important for mental health as this remains a scientific and 
observation-based way of exploring social interaction between professionals and those seeking treatment (O'Reilly \& Lester, 2017), while still recognising that mental states are constituted through interpersonal interactions (Georgaca, 2014).

Applied CA's practical focus on language via naturally occurring data results in real-world problems being better understood. In therapeutic contexts, the most common types of naturally occurring data are recordings of therapy or counselling sessions, and the clinical notes accompanying them. This focus is important in therapy as it shines a spotlight on what happens in practice, allowing important reflections on best practices and where communication can be improved or changed to be more therapeutically effective.

In health settings, there has been a focus on delivering interventions based on 'best' evidence (Rycroft-Malone et al., 2004). We suggest that Applied CA is the best kind of evidence available for counselling and therapy, and the use of naturally-occurring data ensures this is fundamentally embedded in the evidence produced. Arguments have been proposed that best evidence includes clinical expertise and patient values when making health decisions (Sackett et al., 1996), and by using CA evidence, practitioners can pay attention to all parties, which can encourage therapists to be mindful of their use of language (Strong et al., 2008). Such close attention to the social interaction encourages clinicians to reflect on the in-situ decisions, which can be especially useful for guiding practice and facilitating training programmes (Kiyimba \& O'Reilly, 2016).

Importantly, Applied CA is not primarily concerned with 'effectiveness' or with the competencies of the therapist, but instead it focuses on how the interaction is constructed, thereby examining what goes on between the different parties (Streeck, 2010). That is, from a counselling and psychotherapy perspective, Applied CA does not focus specifically on therapists' insights or assumptions, but instead looks at how therapeutic conversations work (Madill et al., 2001). 
Thus, the goal is not to evaluate a therapist's practices or dictate to therapists how they should conduct their work; rather, Applied CA serves to reveal how therapeutic interactions operate in the real world so that therapists can reflect on what is working well and how/if changes might be beneficial (Streeck, 2010).

\section{Why does CA encourage partnership working?}

Qualitative research can and should make a meaningful contribution to the evidence-base (Lester \& O'Reilly, 2015), yet this is only possible if the evidence is palatable for the practice-based audiences it is aimed at (Green, 2008). In our writing, we have cautioned that some CA studies have failed to reach counsellors and therapists because of its specialised vocabulary (Lester \& O'Reilly, 2018). Not surprisingly, then, as clinicians have begun to embrace the value of $\mathrm{CA}$, they have called for more accessible explanations and greater involvement of practitioners in the research process (e.g., see our recent book designed to help people new to the field understand the practices and processes of undertaking this work, Lester \& O'Reilly, 2019). For instance, in recent contributions, psychiatrist Karim (2015) noted that Applied CA translates very usefully in to clinical practice, but needs to reach greater practice-based audiences. Further, psychotherapist Streeck (2010, p.179) reported that "the therapeutic endeavour cannot be accounted for as a manifestation of dispositions anchored in the biology of the actors, but is at each moment interactively produced" and therefore CA can identify the practices of the therapist and client in their production of a therapeutic reality. While practitioners recognise that there may be some theoretical tensions, such as that between psychoanalytic theory and the practice of $\mathrm{CA}$, it is still positioned as a tool that is helpful in shaping interactions with clients and one that can lead to conceptual rethinking (Peräkylä, 2011).

Given that Applied CA researchers frequently engage practitioners either as research partners, advisors, or interactive participants, the applied messages are informed by clinical practice directly. Already, practitioners working in 
clinical fields are beginning to promote the utility of CA for better understanding therapeutic interaction and mental health (Karim, 2015; Kiyimba, 2015;

Peräkylä, 2011; Streeck, 2010) and see value in working collaboratively with CA researchers on clinically relevant problems of practice. Practically, partnering with Applied CA scholars, often involves simply reaching out to people with shared interests and inviting them to consider participating in a study that directs a problem of practice of relevance to CA. Designing an Applied CA study and/or engaging in analysis of data solo is not ideal. Rather, it is useful to engage in collaboration throughout the process, particularly given that learning how to do CA is somewhat challenging and requires support. Indeed, CA researchers encourage sharing of ideas through 'data sessions' so multiple perspectives and analytic expertise is applied to the data. Because of this CA has some communities of practice, and more are emerging. Some are broad, (such as the International Society for Conversation analysis;

https://isca.clubexpress.com/), some focus on the process of improving institutional practices (such as the Conversation Analytic Role-play Method [CARM]; http://www.carmtraining.org/) and others are more specific to certain areas, like autism (such as Conversation Analysis Research in Autism [CARA]; https://www2.le.ac.uk/departments/psychology/research/child-mentalhealth/cara-1)

\section{What are Useful Examples of 'Applied CA'?}

There is now a considerable CA literature in therapy and counselling, and many examples whereby useful recommendations have been made by exploring the actual practices of therapy. We offer only a few such examples here:

- A fundamental competency in counselling and therapy, is active listening. However, in the literature it is not always clear what constitutes this skill or how it can be achieved. In his Applied CA work, Hutchby (2005) demonstrated that in child counselling, active listening is displayed by the counsellor, and achieved in different ways.

- In our own work, we have also made recommendations to therapists based on CA's close examination of what is achieved. For example, we 
attended to the role of children in family therapy, and identified ways in which children passively or actively resisted participation (O'Reilly \& Parker, 2013). By drawing attention to the subtleties of the interaction, therapists can become more aware of children's attention during a session.

- In CA work on radio counselling, Thell and Peräkylä (2018) attended to how such encounters were closed down, while doing therapeutic work in the public sphere. The showed that callers were asked to single out useful aspects of the encounter and noted that by requiring the formulation of conclusions by the caller, there was a recognition of their entitlement to judge the outcomes, but also checked and reviewed the caller's understanding of the problem.

- In a study of Cognitive Behaviour Therapy, Antaki et al. (2004) demonstrated that there can be resistance by a client with the therapist's formulation of the problem, and through this disaffiliation with asserts a position of the clients felt experience. Thus, CA illuminated how there was a mis-match between understandings of how the 'problem' was to be handled, and identified ways that formulating client problems, should resistance not occur, might allow therapists to close expositions of the problem and provide a 'normalising gloss'.

\section{What can we conclude about the value of CA?}

Our perspective is simply this: counselling and psychotherapy are fields that need Applied CA research, both in terms of reading evidence to inform practice and in terms of practitioners engaging with the approach to help build the evidence-base. Applied CA is an especially valuable form of evidence for therapists and counsellors to demonstrate to commissioners and policy makers what works well in their work (Streeck, 2010). We acknowledge that in some circles qualitative evidence has not been rated as highly as it should. Nonetheless, CA has its own internal quality systems, allowing for a case to be made for its rigour and quality (Peräkylä, 2011, b). To be truly 'Applied', CA 
scholars need to continue forming meaningful partnerships with practitioners and engage in the evidence-based debate. As a CA and clinical practice community, we need to continue to showcase collaboratively what this approach can offer. Despite its utility, we have been surprised that relatively few people working in therapeutic environments are familiar with CA. We therefore encourage therapists and counsellors to explore what CA has to offer and to think about how the evidence produced via a CA-informed study might provide useful insights about therapeutic work. Indeed, we suggest that CA is a highly relevant methodology to the readers of this journal and worthy of careful consideration. 


\section{References}

Antaki, C. (2011). Six kinds of applied conversation analysis, in C. Antaki, (Ed). Applied Conversation Analysis: Intervention and change in institutional talk. (pp: 1-14). Hampshire: Palgrave MacMillan.

Antaki C. , Leudar I and Barnes, R. (2004) Trouble in agreeing on a client's problem in a cognitive-behavioural therapy session. Rivista di Psicolinguistica Applicata. 4, 127-138

Bozatzis, N., and Dragonas, T. (2011). Introduction, in N Bozatzis and T Dragonas (Eds), The discursive turn in social psychology (pp: 15-23), Ohio: Taos Institute Publications.

Drew, P., Chatwin, J. \& Collins, S. (2001). Conversation analysis: A method for research into interactions between patients and health-care professionals. Health Expectations, 4(1), 58-70

Georgaca, E. (2014). Discourse analytic research on mental distress: A critical overview. Journal of Mental Health, 23(2), 55-61.

Green, J. (2008). Making research relevant: If it is an evidence-based practice, where's the practice-based evidence? Family Practice, 25, i20-i24.

Harrè, R. (2003). The discursive turn in social psychology. In D. Schiffrin, D. Tannen and H. Hamilton. (Eds). The Handbook of Discourse Analysis (pp: 688706). Oxford: Blackwell Publishing.

Hutchby, I. (2005). 'Active listening': formulation and the elicitation of feelingstalk in child counselling. Research on Language and Social Interaction, 38(3), 303-329 
Karim, K. (2015). The value of conversation analysis: A child psychiatrist's perspective, in M. O'Reilly \& J. N. Lester (Eds.), The Palgrave handbook of child mental health: Discourse and conversation studies (pp. 25-41). Basingstoke: Palgrave MacMillan.

Kiyimba, N. (2016). Using discourse and conversation analysis to study clinical practice in adult mental health, in M O'Reilly \& JN Lester (Eds.), The Palgrave handbook of adult mental health. Discourse and conversation studies, (pp. 4563). Basingstoke: Palgrave MacMillan.

Kiyimba, N., Lester, J., \& O'Reilly, M. (in press). Using naturally occurring data in qualitative health research: A practical guide. Springer

Kiyimba, N., and O'Reilly, M. (in press). Reflecting on what 'you said' as a way of reintroducing difficult topics in child mental health assessments. Child and Adolescent Mental Health

Kiyimba, N., \& O'Reilly, M. (2016). The value of using discourse analysis to explore counselling and therapeutic interactions, in O'Reilly, M., \& Lester, J. (Eds.), The Palgrave handbook of adult mental health: Discourse and conversation studies (pp: 520-539). Basingstoke: Palgrave Macmillan.

Kiyimba, N., O'Reilly, M. \& Lester, J. (in press). Agenda setting with children using the three wishes technique. Journal of Child Health Care,

Lester, J., \& O'Reilly, M. (2019). Applied conversation analysis: Social interaction in institutional settings. Thousand Oaks, CA: Sage.

Lester, J., \& O'Reilly, M. (2015). Is evidence-based practice a threat to the progress of the qualitative community? Arguments from the bottom of the pyramid. [Special issue; $20^{\text {th }}$ Anniversary edition] Qualitative Inquiry, 21(7), 628632. 
Lester, J., O’Reilly, M., Kiyimba, N., \& Wong, J. (in press) Discursive Psychology: Implications for counselling psychology. The Counseling Psychologist

Madill, A., Widdicomb, S., \& Barkham, M. (2001) The potential of conversation analysis for psychotherapy research. The Counselling Psychologist, 29, 413434.

McLeod, J. (2001). Qualitative Research in Counseling and Psychotherapy. London: Sage.

O'Reilly, M. \& Lester, J (2017). Examining mental health through social constructionism: The language of mental health. Basingstoke: Palgrave.

O'Reilly, M., \& Lester, J. (2016). Building a case for good parenting in a family therapy systemic environment: Resisting blame and accounting for children's behaviour. Journal of family therapy, 38(4), 491-511

O'Reilly, M., \& Parker, N. (2013). 'You can take a horse to water but you can't make it drink': Exploring children's engagement and resistance in family therapy. Contemporary Family Therapy, 35(3), 491-507

Parker, N. \& O'Reilly, M. (2012). 'Gossiping' as a social action in family therapy: The pseudo-absence and pseudo-presence of children. Discourse Studies, 14 (4) 1-19.

Peräkylä, A. (2011). A psychoanalyst's reflection on conversation analysis's contribution to his own therapeutic talk, in C. Antaki, (Ed.), Applied Conversation Analysis: Intervention and change in institutional talk. (pp: 222242). Hampshire: Palgrave MacMillan 
Peräkylä, A. (2011 b). Validity in research on naturally occurring social interaction, in D. Silverman (Ed.), Qualitative research (3 ${ }^{\text {rd }}$ edition, pp. 365-382). London, UK: Sage.

Priebe, S., \& McCabe, R. (2008). Therapeutic relationships in psychiatry: The basis of therapy or therapy in itself? International Review of Psychiatry, 20 (6), 521-526.

Roy-Chowdhury, S. (2006). How is the therapeutic relationship talked into being? Journal of Family Therapy, 28, 153-174.

Rycroft-Malone, J., Harvey, G., Seers, K., Kitson, A., McCormack, B., \& Titchen, A. (2004). An exploration of the factors that influence the implementation of evidence into practice. Issues in Clinical Nursing, 13, 913-924.

Sackett, D., Rosenberg, W., Gray, J., Haynes, R., \& Richardson, W. (1996) Evidence-based medicine: What it is and what it isn't. British Medical Journal, $312,71-72$

Streeck, U. (2010). A psychotherapist's view of conversation analysis, in A. Peräkylä, C. Antaki, S. Vehvilainen, \& I Leudar (Eds.), Conversation Analysis and psychotherapy (pp: 173-187). Cambridge: Cambridge University Press.

Strong, T., Busch, R., \& Couture, S. (2008). Conversational evidence in therapeutic dialogue. Journal of Marital and Family Therapy, 34(3), 388-405.

Thell, N. and Peräkylä, A. (2018). 'What are you taking away with you?' Closing radio counselling encounters by reviewing progress. Discourse Studies,

Tseliou, E. (2013). A critical methodological review of discourse and conversation analysis studies of family therapy. Family Process, 52(4), 653-67 